\title{
Determination of Aromatic Aldehydes by High Performance Liquid Chromatography after Precolumn Fluorescent Derivatization with 4,5-Dimethyl-o-phenylenediamine
}

\author{
Masatoki Katayama, Yoshio Mukai and Hirokazu TaniguchI
}

Meiji College of Pharmacy, Nozawa, Setagaya, Tokyo 154

\begin{abstract}
A new sensitive method for the determination of aromatic aldehydes (benzaldehyde, $0 \cdot, m$ - and $p$-hydroxybenzaldehydes and vanillin) is described which employs high performance liquid chromatography (HPLC) with fluorometric detection. Aromatic aldehydes were derivatized with 4,5-dimethyl-o-phenylenediamine (DMPD) in an acidic medium, and the resultant fluorescent benzimidazole derivatives were separated on a reversed phase column (Zorbax ODS) with $0.02 \mathrm{M}$ acetate buffer( $\mathrm{pH} 4.0$ )-methanol (1:1) containing $5 \mathrm{mmol} \mathrm{1}^{-1} \mathrm{n}$-dodecyltrimethylammonium bromide as a mobile phase. The detection limits of aromatic aldehydes were in the range from 0.05 to 2.5 $\mathrm{ng} \mathrm{m}^{-1}$. This method was applied to the determination of vanillin in commercial ice cream.
\end{abstract}

Keywords Fluorometric detection, aromatic aldehyde, 4,5-dimethyl-o-phenylenediamine, high performance liquid chromatography, vanillin, ice cream

Aromatic and aliphatic aldehydes are directly determined by high performance liquid chromatography (HPLC) with photometric detection ${ }^{1-9}$ or determined using the precolumn derivatization methods for HPLC with photometric detection. ${ }^{10-17}$ Dansyl hydrazine was used as a derivatization reagent of aromatic and aliphatic aldehydes for fluorometric detection ${ }^{18,19}$, but no other detailed studies are reported on the application of aromatic aldehyde determination. 4,5-Dimethoxy-o-phenylenediamine ${ }^{20}$ was applied to the determination of phenylacetaldehyde and $p$ hydroxyphenylacetaldehyde which were produced from bestatin and $p$-hydroxybestatin.

We already reported the fluorometric method for the determination of aromatic aldehydes with 4,5-dimethyl$o$-phenylenediamine (DMPD) in a previous paper. ${ }^{21}$ In the present investigation, the fluorescence reaction was applied to the precolumn derivazation of aromatic aldehydes. The proposed method has been shown to be a powerful technique for selectively enhancing the detectability of aromatic aldehydes in HPLC. This method was applied to the determination of vanillin in ice cream.

\section{Experimental}

\section{Reagents, HPLC apparatus and conditions}

All reagents were of reagent grade (Japan Industrial Standards), unless otherwise noted. Double distilled and deionized water was used throughout. Com- mercial aldehydes were purified by recrystallization or distillation. Stock solutions of aromatic aldehydes were prepared by dissolving $10 \mathrm{mg}$ of aldehydes in 20 $\mathrm{ml}$ of ethanol and diluting with water to $100 \mathrm{ml}$. DMPD solution was prepared by dissolving $30 \mathrm{mg}$ of DMPD in $3 \mathrm{ml}$ of $0.5 \mathrm{M}$ sulfuric acid and diluting with water to $100 \mathrm{ml}$. This solution was stable for $2 \mathrm{~d}$ in the dark. HPLC apparatus and conditions were as follows. Pump: Hitachi pump 635A equipped with a Hitachi high pressure sampling valve (200 $\mu \mathrm{l}$ loop); precolumn: Zorbax ODS $(50 \times 4.0 \mathrm{~mm}$ i.d., $7 \mu \mathrm{m}$, DuPont); analytical column: Zorbax ODS (250×4.0 $\mathrm{mm}$ i.d., $7 \mu \mathrm{m}$, DuPont); sample volume: $20 \mu \mathrm{l}$; column temperature: $30^{\circ} \mathrm{C}$; detector: Shimadzu RF-530 fluorescence spectromonitor (ex. $330 \mathrm{~nm}$, em. $400 \mathrm{~nm}$ ); mobile phase: $0.02 \mathrm{M}$ acetate buffer ( $\mathrm{pH} 4.0$ )-methanol (1:1) containing $5 \mathrm{mmol} \mathrm{l}^{-1} n$-dodecyltrimethylammonium bromide; flow rate: $1.0 \mathrm{ml} \mathrm{min}^{-1}$.

\section{Precolumn derivatization of aromatic aldehydes ${ }^{21}$}

To $1.0 \mathrm{ml}$ of DMPD solution is added $1.0 \mathrm{ml}$ of sample solution containing aromatic aldehyde in a glass stoppered test tube. The mixture is shaken well and heated in a boiling water bath for $50 \mathrm{~min}$, cooled to room temperature and mixed with $0.5 \mathrm{ml}$ of $0.5 \mathrm{M}$ sodium hydroxide solution. Twenty microliters of the mixture is injected to the HPLC apparatus.

\section{Procedure for the determination of vanillin in commercial ice cream}

Twenty milliliters of dichloromethane is poured onto 
$1 \mathrm{~g}$ of ice cream, and the mixture is shaken well for 5 min. The mixture is filtered through a Celite 545 (Wako, Japan), and the residue on the Celite is washed with $50 \mathrm{ml}$ of dichloromethane. The filtrate and washings are combined, the solvent is concentrated at below $40^{\circ} \mathrm{C}$ to about $2-3 \mathrm{ml}$ and then it is evaporated to dryness in a stream of nitrogen. The residue is dissolved in $10 \mathrm{ml}$ of water and the solution is filtered through a membrane filter $(0.45 \mu \mathrm{m})$. The filtrate is treated by the precolumn derivatization procedure prior to injection to the HPLC apparatus.

\section{Results and Discussion}

\section{Precolumn derivatization}

Precolumn derivatization was made by reacting aromatic aldehydes with DMPD in diluted sulfuric acid medium followed by addition of sodium hydroxide solution. ${ }^{21}$ Concentration of sodium hydroxide affected the retention times of DMPD derivatives of aromatic aldehydes since the reaction mixture was directly subjected to HPLC. To obtain the reproducible retention times, the range of $0.4-1.0 \mathrm{M}$ sodium hydroxide were required as the reagent. Therefore, 0.5 $\mathrm{ml}$ of $0.5 \mathrm{M}$ sodium hydroxide was used.

\section{Separation of DMPD derivatives}

In order to determine the separation conditions for aromatic aldehydes, benzaldehyde, $o-, m$ - and $p$ hydroxybenzaldehydes and vanillin were used as the model compounds. Aqueous methanol, ethanol, acetonitrile, tetrahydrofuran, acetate buffer and their mixtures were examined as possible mobile phases for the reversed phase column. The mixture of $0.02 \mathrm{M}$ acetate buffer ( $\mathrm{pH} 4.0$ )-methanol (1:1) gave relatively satisfactory resolution of the peaks for the DMPD derivatives of aromatic aldehydes except $p$-hydroxybenzaldehyde and vanillin. By the addition of $n$ dodecyltrimethylammonium bromide to the acetate buffer-methanol mixture, better separation was obtained (Fig. 1). Consequently, $0.02 \mathrm{M}$ acetate buffer (pH 4.0)-methanol (1:1) containing $5 \mathrm{mmol} \mathrm{l}^{-1} n$-dodecyltrimethylammonium bromide was used as a model mobile phase. The retention times of DMPD derivatives of aromatic aldehydes were increased by the use of mobile phases of $\mathrm{pH} 5$ or above, and the mobile phase of pH 3.2 gave unsatisfactory resolution of the


each DMPD derivatives were between $7 \mathrm{~min}$ and 39 min and a good separation of the peaks was obtained (Fig. 2).

By the use of the mobile phase of the ratio of the methanol to buffer (pH 4.0) of 1:1, satisfactory separation of the peaks for all the DMPD derivatives was obtained (Fig. 3).

Under the flow rate of $1.0 \mathrm{ml} \mathrm{min} \mathrm{m}^{-1}$, the retention times of DMPD derivatives were between 7 and 39 min. Column temperature was independent on the

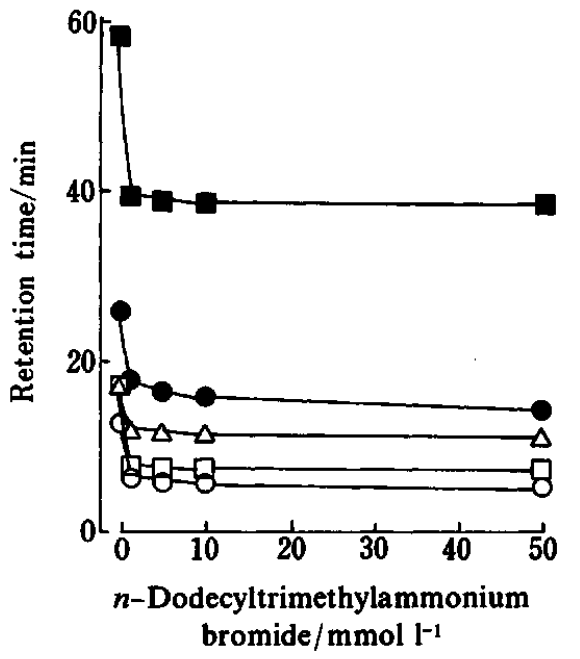

Fig. 1 Effect of $n$-dodecyltrimethylammonium bromide concentration in mobile phase on the retention times of DMPD derivatives. The mobile phases consisting of $0.02 \mathrm{M}$ acetate buffer (pH 4.0)-methanol (1:1) and $n$ dodecyltrimethylammonium bromide of various concentrations $\left(0-50 \mathrm{mmol}^{-1}\right)$ were used. $\mathrm{O}$, p-hydroxybenzaldehyde; $\square$, vanillin; $\Delta$, m-hydroxybenzaldehyde; $O$, benzaldehyde; $\mathbf{Q}, o$-hydroxybenzaldehyde.

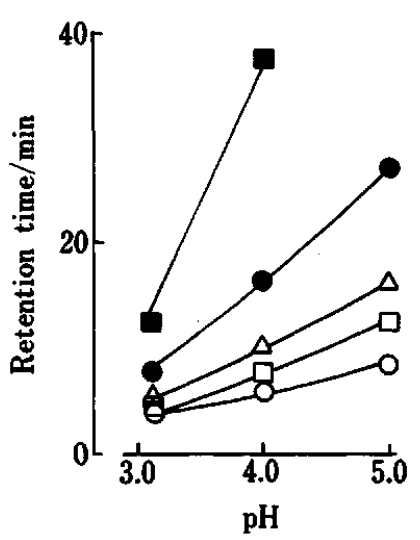

Fig. 2 Effect of pH of mobile phase on the retention times of DMPD derivatives. The mobile phases consisting of $0.02 \mathrm{M}$ acetate buffer ( $\mathrm{pH} 3.2-5.0$ )-methanol (1:1) containing $5 \mathrm{mmol}^{-1} n$-dodecyltrimethylammonium bromide were used. Symbols used are the same as those in Fig. 1.

separation of the peaks at $25^{\circ} \mathrm{C}$ to $60^{\circ} \mathrm{C}$. Consequently, the temperature of $30^{\circ} \mathrm{C}$ was conveniently selected as the proposed method.

\section{Determination of DMPD derivatives}

The fluorescence excitation and emission spectra of each DMPD derivative of aromatic aldehydes in the HPLC eluates are shown in Fig. 4. Excitation and emission maxima and relative fluorescence intensities are shown in Table 1. The excitation and emission 


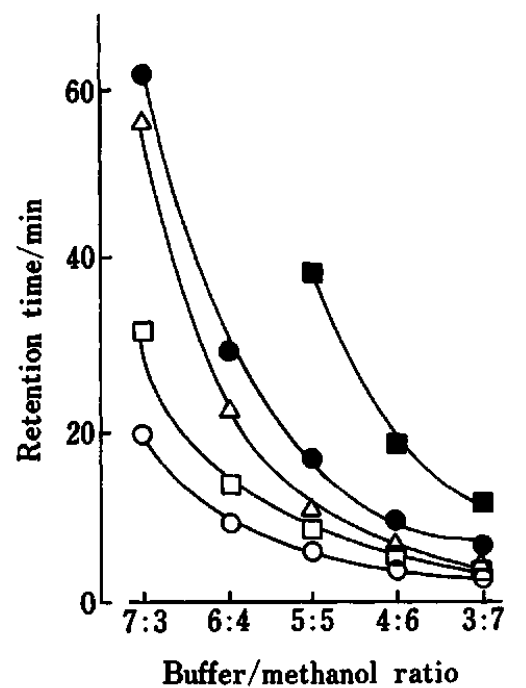

Fig. 3 Effect of methanol concentration in mobile phase on the retention times of DMPD derivatives. The mobile phases consisting of $5 \mathrm{mmol} \mathrm{l}^{-1} n$-dodecyltrimethylammonium bromide were used. Methanol concentrations are shown as buffer/methanol ratios on the abscissa. Symbols used are the same as those in Fig. 1

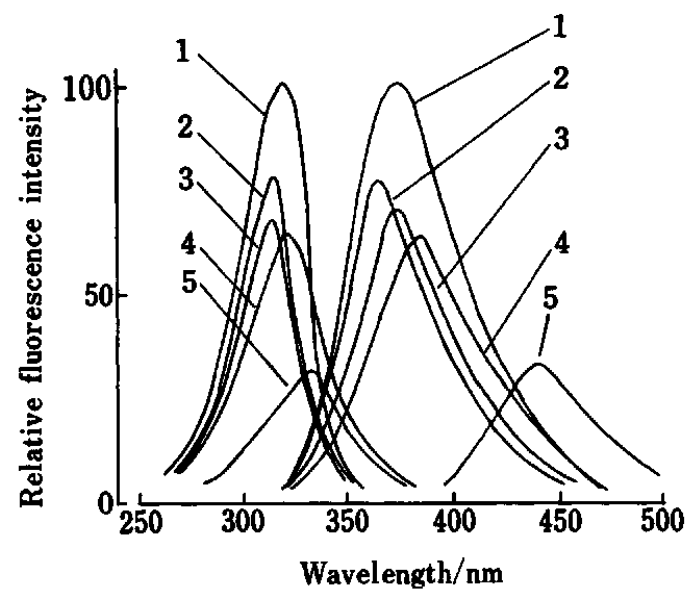

Fig. 4 Excitation and emission spectra of DMPD derivatives of aromatic aldehydes in eluate. I, $p$-hydroxybenzaldehyde $\left(5 \times 10^{-6} \mathrm{~mol} \mathrm{l}^{-1}\right) ; 2, m$-hydroxybenzaldehyde $\left(5 \times 10^{-6}\right.$ mol $\left.1^{-1}\right) ; 3$, benzaldehyde $\left(5 \times 10^{-6} \mathrm{~mol} \mathrm{l}^{-1}\right) ; 4$, vanillin $(5 \times$ $\left.10^{-6} \mathrm{~mol} \mathrm{l}^{-1}\right) ; 5, o$-hydroxybenzaldehyde $\left(2.5 \times 10^{-6} \mathrm{~mol} \mathrm{l}^{-1}\right)$.

Table 1 Excitation and emission maxima and relative fluorescence intensities of DMPD derivatives of aldehydes

\begin{tabular}{lccr}
\hline \multicolumn{1}{c}{ Aldehyde $^{\mathrm{a}}$} & $\mathrm{Ex}_{\max } / \mathrm{nm}$ & $\mathrm{Em}_{\text {max }} / \mathrm{nm}$ & R.F.I. \\
\hline Benzaldehyde & 315 & 372 & 70.2 \\
$o$-Hydroxybenzaldehyde & 340 & 440 & 5.1 \\
$m$-Hydroxybenzaldehyde & 315 & 365 & 78.4 \\
$p$-Hydroxybenzaldehyde & 320 & 375 & 100.0 \\
Vanillin & 325 & 385 & 64.2 \\
\hline
\end{tabular}

a. Concentrations of $5 \times 10^{-6} \mathrm{~mol}^{-1}$ were taken.



Fig. 5 Separation of DMPD derivatives. Aromatic aldehydes taken: $1 \mu \mathrm{g} \mathrm{ml}^{-1}$ each. $1, \boldsymbol{p}$-hydroxybenzaldehyde; 2 , vanillin; $3, m$-hydroxybenzaldehyde; 4 , benzaldehyde; 5 , $o$-hydroxybenzaldehyde.

Table 2 Retention times of DMPD derivatives of aldehydes

\begin{tabular}{lc}
\hline Aldehydes & Retention time/min \\
\hline Benzaldehyde & 16.4 \\
$o$-Hydroxybenzaldehyde & 39.0 \\
$m$-Hydroxybenzaldehyde & 11.2 \\
$p$-Hydroxybenzaldehyde & 6.0 \\
Vanillin & 7.6 \\
$o$-Methoxybenzaldehyde & 10.0 \\
$m$-Methoxybenzaldehyde & 26.5 \\
$p$-Methoxybenzaldehyde & 13.0 \\
3,4-Dimethoxybenzaldehyde & 13.6 \\
Furfural & 18.0 \\
5-(Hydroxymethyl)-2-furfural & 9.2 \\
\hline
\end{tabular}

wavelength for the HPLC detection were settled at 330 $\mathrm{nm}$ and $400 \mathrm{~nm}$.

Figure 5 shows the chromatogram of DMPD derivatives obtained with the recommended procedure. Table 2 shows the retention times of 11 DMPD derivatives of aromatic aldehydes.

The limits of detection of aromatic aldehydes in the present procedure were as follows: $0.05 \mathrm{ng} \mathrm{ml}^{-1}$ for benzaldehyde, $m$ - and $p$-hydroxybenzaldehydes and vanillin and $2.5 \mathrm{ng} \mathrm{ml}^{-1}$ for $o$-hydroxybenzaldehyde at a signal-to-noise ratio of 2 , respectively.

A linear relationship was obtained between the concentration and the peak height in the range of $0.0001-30 \mu \mathrm{g} \mathrm{ml}^{-1}$ vanillin. The relative standard deviation for the determination of $0.05 \mu \mathrm{g} \mathrm{ml}^{-1}$ vanillin was $3.38 \%(n=6)$.

\section{Determination of vanillin in commercial ice cream}

Vanillin is used as a food additive and in cosmetics. Gas chromatography ${ }^{22}, \mathrm{HPLC}^{3}$ and photometry ${ }^{23}$ are available as methods for the determination of vanillin 
Table 3 Determination of vanillin in ice cream samples

\begin{tabular}{ccc}
\hline Sample & Found $/ \mu \mathrm{g} \mathrm{ml}^{-1}$ & RSD $^{\mathbf{a}}, \%$ \\
\hline A & 19.4 & 7.32 \\
B & 7.1 & 7.91 \\
C & 3.4 & 8.09 \\
D & 5.7 & 8.20 \\
E & 1.0 & 8.31 \\
\hline
\end{tabular}

a. Values obtained by 6 runs.

in foodstuffs.

These methods require some tedious pretreatments. Therefore, we attempted to apply our proposed method to the determination of vanillin in ice cream. The effect of solvent on extraction of vanillin from commercial ice cream was first examined for the pretreatment of sample. Dichloromethane, chloroform, ethyl acetate, acetone, ethanol and acetonitrile were tested. Dichrolomethane and chloroform were found to be superior to the others. In view of the highly toxic properties, dichloromethane was selected as the solvent for extraction of vanillin.

The vanillin contained in five commercial ice cream samples were determined by the recommended procedure. The results are shown in Table 3. The amount of vanillin in the preparations were $1.0-19.4 \mu \mathrm{g} \mathrm{ml}^{-1}$. The recovery of vanillin added to sample A $(1.0 \mu \mathrm{g}$ $\left.\mathrm{ml}^{-1}\right)$ was $90.9 \%(n=6)$ and the relative standard deviation was $7.22 \%(n=6)$. Thus, the present HPLC method permits the determination of vanillin in ice cream with a simpler procedure than the published methods. $3,22,23$

The HPLC method using DMPD is probably one of the best methods for the determination of vanillin in terms of sensitivity, reproducibility and simplicity.

\section{References}

1. L. Olsson and O. Samuelson, J. Chromatogr., 106, 139 (1975).
2. H. Komae and N. Hayashi, J. Chromatogr., 114, 258 (1975).

3. Pharmaceutical Society of Japan (ed.), "Standards of Analysis for Hygenic Chemists", Kanehara Shuppan Co., Tokyo, p. 384 (1980).

4. M. Popl, V. Dolansky and T. Fahnlich, J. Chromatogr., 148, 195 (1978).

5. J. H. Block and H. Levine, J. Chromatogr., 166, 313 (1978).

6. E. Roggendorf and R. Spatz, J. Chromatogr., 204, 263 (1981).

7. A. Herrmann and M. Stockli, J. Chromatogr., 246, 313 (1982).

8. E. Burtsher, H. Binder, R. Concin and O. Bobtler, J. Chromatogr., 252, 167 (1982).

9. L. Severe, L. Piovetti and N. Longuemard, $J$. Chromatogr., 259, 319 (1983).

10. H. Katsuki, Anal. Biochem., 24, 112 (1966).

11. F. A. Fitzpatric, S. Siggia and J. Dingman, Anal. Chem., 44, 2211 (1972).

12. M. A. Carey and H. E. Persinger, J. Chromatogr. Sci., 10, 537 (1972).

13. L. J. Papa and L. P. Turner, J. Chromatogr. Sci, 10, 747 (1972).

14. L. J. Papa and E. Tal, J. Chromatogr. Sci., 10, 750 (1972).

15. S. Selim, J. Chromatogr., 136, 271 (1977).

16. K. Kuwata, M. Uevori, H. Yamasaki and Y. Kuge, Anal. Chem., 55, 2013 (1983).

17. T. H. Jupillie, Amer. Lab., 8, 85 (1976).

18. K. Tani and Y. Suzuki, Bunseki Kagaku, 32, 373 (1983).

19. L. Johnson, B. Josefsson, P. Marstop and G. Eklund, Int. J. Environ. Anal. Chem., 9, 7 (1981).

20. J. Ishida, M. Yamaguchi, H. Kai, Y. Ohkura and $M$. Nakamura, J. Chromatogr., 305, 381 (1984).

21. M. Katayama, Y. Mukai and H. Taniguchi, Anal. Sci., 3, 369 (1987).

22. Pharmaceutical Society of Japan (ed.), "Standards of Analysis for Hygenic Chemists", Kanehara Shuppan Co., Tokyo, p. 383 (1980).

23. "Methods of Analysis of AOAC", 14th ed., method No. 19.023 , p. 356 (1984). 